
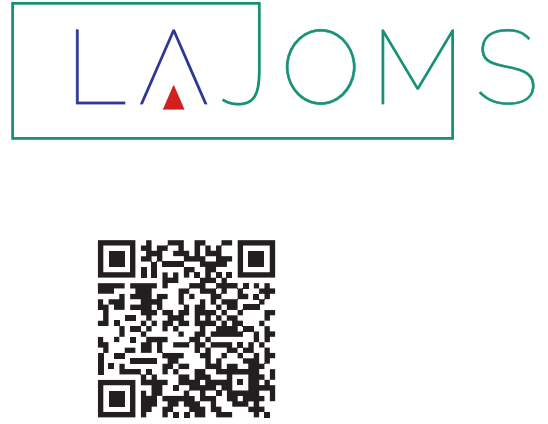

Enero - Marzo 2022 Vol. 2, núm. 1 / p. 5

* Presidente de la Asociación Latinoamericana de Cirugía y Traumatología Buco Maxilofacial (ALACIBU) 2022-2023. Ex-Presidente de la Asociación Mexicana de Cirugía Bucal y Maxilofacial A.C. AMCBM.

doi: $10.35366 / 103402$

\title{
LAJOMS y la Pandemia
}

\author{
LAJOMS and the Pandemic
}

César Villalpando Trejo*

Apreciables amigos y colegas de nuestra querida ALACIBU, reciban una cordial felicitación por este inicio de nuevo año 2022 y que para ustedes y su familia esté lleno de éxitos y bendiciones, principalmente salud.

Es un honor para mí el dirigirme a ustedes por primera ocasión como presidente de la Asociación y poder plasmar en unas líneas el beneplácito y al mismo tiempo el compromiso que esto conlleva, ya que después de una situación tan inesperada como ha sido la pandemia, hemos tenido que abstenernos de actividades que hasta hace dos años considerábamos tan triviales como estar reunidos y compartir un abrazo o un simple saludo de mano, que tanto nos caracteriza como latinoamericanos, y tratar de adaptar nuestro acercamiento a una separación física pero que nos permitirá reencontrarnos y saludarnos en los eventos que se irán organizando en los diferentes países que integran nuestra región geográfica; ojalá que con la menor incidencia de COVID-19 y la aplicación masiva de vacunas entre nuestros países hermanos podamos reunirnos en nuestro XXII CIALACIBU de Cartagena 2022.

En esta ocasión, tengo la oportunidad de escribir estas líneas en el segundo volumen de nuestra revista LAJOMS, la cual después de muchos planes y administraciones pasadas fue concretada con el Dr. Raúl Parra, Presidente saliente de ALACIBU, y por el Dr. Luis Lobo, Editor en jefe de la revista, ambos reciban un reconocimiento público así como todo su equipo de trabajo por la dedicación y esmero para hacer posible estas ediciones que de hoy en adelante se volverán nuestro órgano científico oficial, con el que académicamente nos reconocerán a nivel mundial. Por lo que pido a cada uno de nuestros agremiados el difundir su existencia entre nuestros colegas, residentes o estudiantes y también incentivarlos a participar como autores de publicaciones científicas que nos permitan trascender como gremio.
Nuestro mundo y nuestra sociedad han tenido que cambiar drásticamente en un periodo muy corto de tiempo en pro de conservar lo más valioso que un humano puede poseer, tal como es la salud; sin embargo, siempre hemos sido testigos de que después de una tormenta siempre Ilega la calma y ello nos permite revaluar nuestras acciones y mejorar aquéllas que no estaban bien cimentadas, tal como hoy en día sucede; ahora tenemos la oportunidad de retomar los valores más preciados que tiene el ser humano, tales como la gratitud, hermandad, amistad e igualdad, si algo nos han enseñado estos 24 meses de pandemia es que el dinero no es garantía de salud ni de que podamos estar reunidos con nuestros seres queridos. Cuántos de nosotros no hemos podido abrazar a nuestros padres, o darles un simple beso en la mejilla sin tener el miedo de ocasionarles un daño físico relacionado principalmente por nuestra profesión de alto riesgo, o cuántos de nosotros no pudimos despedir o estar cerca de un ser querido en sus últimos momentos por esta enfermedad. Estas situaciones nos servirán como un parteaguas que nos permitirá ser una mejor sociedad y poder poner las cosas con su justo valor.

Compartamos a las nuevas generaciones nuestras experiencias, permitiendo así que aprendan las cosas buenas y evitar que cometan nuestros errores. Esto con el único objetivo de dejar un mundo mejor para los que están por venir y que en un futuro digan que después de la pandemia el mundo fue mejor.

Éxito a cada uno de ustedes este nuevo año y bendecido 2022.

\author{
Correspondencia: \\ Dr. César Villalpando Trejo \\ E-mail: cesarvi@att.net.mx
}

